\title{
ADSORPSI AMONIA DARI LIMBAH CAIR INDUSTRI PENYAMAKAN KULIT MENGGUNAKAN ABU TERBANG BAGAS
}

\section{ADSORPTION OF AMMONIA FROM TANNERY WASTEWATER USING BAGASSE FLY ASH}

\author{
Rihastiwi Setiya Murti*, Christiana Maria Herry Purwanti, Suyatini \\ Balai Besar Kulit, Karet, dan Plastik, Yogyakarta \\ *E-mail: rihastiwi@gmail.com
}

Diterima: 21 Oktober 2013 Direvisi: 12 Desember 2013 Disetujui: 20 Desember 2013

\begin{abstract}
The aim of this study is to reduce ammonia concentration in tannery wastewater using bagasse fly ash in a batch adsorption system. Experiments were conducted to study the effect of various parameters such as adsorbent dose and contact time. Data analysis was performed by calculating the efficiency of adsorption and fitting the data into Freundlich and Langmuir isotherm models. Correlation coefficient and mean squared error were used to evaluate the performance of the models. From the results, it was found that the operating conditions to achieve an optimum removal efficiency of $45.72 \%$ are 1 hour contact time and 2 grams of bagasse fly ash. The results also indicate that the data fits Langmuir model well where Langmuir constant $\mathrm{Q}^{\circ}, \mathrm{b}$, and correlation coefficient were found to be $0.706 \mathrm{mg} / \mathrm{g}, 0.209 \mathrm{~L} / \mathrm{mg}$, and 0.9424 , respectively.
\end{abstract}

Keywords: Ammonia, adsorption, bagasse fly ash, tannery wastewater

\section{ABSTRAK}

Penelitian ini bertujuan untuk mengurangi kadar amonia dalam limbah cair industri penyamakan kulit menggunakan abu terbang bagas secara batch. Variasi percobaan secara batch yaitu berat abu terbang bagas dan waktu adsorpsi. Analisis data dilakukan dengan penghitungan efisiensi penjerapan dan memasukkan data ke persamaan isotherm Freundlich dan Langmuir. Koefisien korelasi dan mean squared error digunakan untuk mengevaluasi model terbaik. Kondisi optimum adsorpsi amonia secara batch dalam penelitian ini berada pada waktu kontak 1 jam, berat abu terbang bagas 2 gram, dan efisiensi penjerapan 45,72\%. Persamaan yang cocok untuk menggambarkan adsorpsi amonia dalam limbah cair industri penyamakan kulit menggunakan abu terbang bagas ini adalah persamaan Langmuir. Konstanta persamaan Langmuir $\mathrm{Q}^{\circ}, \mathrm{b}$, dan koefisien korelasi yang diperoleh masing-masing $0,706 \mathrm{mg} / \mathrm{g}, 0,209 \mathrm{~L} / \mathrm{mg}$, dan 0,9424.

Kata kunci: Amonia, adsorpsi, abu terbang bagas, limbah cair industri penyamakan kulit

\section{PENDAHULUAN}

Industri penyamakan kulit merupakan industri yang menggunakan bahan kimia dan air dalam jumlah besar. Proses penyamakan kulit dimulai dari proses soaking, liming, deliming, bating, pickling, tanning, dyeing, fatliquoring dan finishing. Dalam proses operasionalnya, industri penyamakan kulit menghasilkan limbah cair, limbah padat dan gas. Dari ketiga limbah tersebut, limbah cair merupakan limbah yang paling banyak dihasilkan. Berkembangnya industri ini bermanfaat bagi pertumbuhan ekonomi, tetapi di sisi lain membawa dampak negatif yaitu menurunnya kualitas lingkungan 
akibat pembuangan limbah yang dihasilkan.

Tahapan proses dalam pengolahan limbah cair industri penyamakan kulit meliputi pengolahan primer, pengolahan sekunder, dan pengolahan tersier. Hasil dari pengolahan limbah primer dan sekunder dapat menurunkan parameter limbah penyamakan kulit seperti BOD, COD, TSS, pH, minyak lemak dan kadar krom total, tetapi kadar amonia dalam limbah cair terolah (outlet) industri penyamakan kulit masih tinggi meskipun telah melalui ketiga tahap pengolahan tersebut. Adanya amoniak dalam limbah cair industri penyamakan kulit disebabkan karena dalam proses penyamakan kulit menggunakan amonium sulfat $\left(\mathrm{NH}_{4}\right)_{2} \mathrm{SO}_{4}$ yaitu pada proses deliming (proses pembuangan kapur). Menurut Rezakazemi et al. (2012), amoniak bersifat racun bagi mayoritas ikan dan teroksidasi secara biologis oleh mikroorganisme menjadi nitrit yang berbahaya bagi manusia. Kadar amonia maksimum yang diperbolehkan dalam buangan air limbah industri penyamakan kulit menurut Gubernur Kepala Daerah Istimewa Yogyakarta (2010) adalah sebagai berikut: $0,5 \mathrm{mg} / \mathrm{L}$ untuk proses penyamakan kulit menggunakan bahan penyamak nabati; $0,2 \mathrm{mg} / \mathrm{L}$ untuk proses penyamakan kulit menggunakan krom dari kulit wet blue dan $0,4 \mathrm{mg} / \mathrm{L}$ untuk proses penyamakan kulit menggunakan krom dari kulit mentah garaman.

Pengolahan tersier untuk menghilangkan polutan dalam air limbah dapat dilakukan dengan cara proses oksidasi, filtrasi membran dan adsorpsi. Adsorpsi diketahui merupakan metode yang paling efisien untuk menghilangkan warna, bau, minyak, dan organik dari air limbah. Karbon aktif menjadi adsorben yang paling banyak dipakai karena kemampuan adsorpsinya yang sangat bagus, tetapi kelemahannya adalah harganya yang mahal. Untuk itu perlu dicari alternatif adsorben dengan harga yang lebih murah, diantaranya dengan memanfaatkan abu terbang bagas.

Abu terbang bagas adalah limbah industri gula yang dihasilkan dari pembakaran bagas di dalam boiler. Limbah ini jumlahnya melimpah dan tidak berharga bagi pabrik gula. Apabila akan memanfaatkan abu terbang bagas, hanya diperlukan biaya pengangkutan. Banyak peneliti telah menggunakan abu terbang bagas sebagai adsorben berbagai polutan dari limbah cair, diantaranya logam (Luo et al., 2011; Wasewar et al., 2009), organik (Subramanian et al., 2013; Srivastava et al., 2008; Lataye et al., 2008), dan COD (Kushwaha et al., 2010).

Penelitian tentang adsorpsi amonia telah banyak dilakukandenganmenggunakan berbagai adsorben. Handayani dan Widyastuti (2009) telah melakukan penelitian tentang adsorpsi amonium pada zeolit berkarbon yang disintesis dari abu dasar batu bara PT. Ipomi. Penelitian yang lain diantaranya adalah penurunan amonia menggunakan arang aktif dari ampas kopi (Irmanto dan Suyata, 2009), penghilangan amonia menggunakan zeolit tipe Clinoptiloit (Jafarpour et al., 2010; Li et al., 2010), zeolit tipe 13X (Zheng et al., 2008), serbuk gergaji (Wahab et al., 2010), abu terbang batu bara dan sepiolit (Uğurlu and Karaoğlu, 2011).

Sejauh penelusuran pustaka yang telah dilakukan, penelitian pengurangan amonia dalam air limbah industri penyamakan kulit telah dilakukan oleh beberapa peneliti tetapi belum ada yang menggunakan cara adsorpsi dengan abu terbang bagas secara batch. Penelitian ini bertujuan untuk mengurangi kadar amonia dalam limbah cair industri penyamakan kulit menggunakan abu terbang bagas secara batch.

\section{BAHAN DAN METODE \\ Bahan Penelitian}

Bahan-bahan yang digunakan dalam penelitian adalah abu terbang bagas dari PT. Madukismo, air limbah penyamakan kulit, asam fosfat $\left(\mathrm{H}_{3} \mathrm{PO}_{4}\right)$ (Merck, p.a.), sodium nitropruside (Merck, p.a.), natrium hidroksida (Merck, p.a.), natrium hipoklorit (Merck, p.a.), fenol (Merck, p.a.), akuades, dan trinatrium sitrat (Merck, p.a.).

\section{Peralatan Penelitian}

Peralatan yang digunakan dalam penelitian yaitu, $\mathrm{pH}$ meter, shaker, spektrofotometer UVVIS 1600 PC.

\section{Metode Penelitian \\ Penentuan waktu kontak dan berat abu terbang bagas optimum}

Disiapkan beberapa buah erlenmeyer dan dimasukkan $100 \mathrm{ml}$ limbah yang konsentrasinya 
telah diukur. Ke dalam masing-masing larutan dimasukkan adsorben dengan variasi berat 0,0 ; 0,$5 ; 1,0 ; 1,5 ; 2,0 ;$ dan 2,5 gram. Larutan diaduk dengan shaker, dilakukan variasi waktu $0 ; 1$; $2 ; 3 ; 4$; dan 5 jam pada suhu ruang. Penelitian dilakukan pada $\mathrm{pH}$ 7. Kadar amonia diuji sebelum dan sesudah adsorpsi menggunakan dengan alat spektrofotometer UV-vis pada $\lambda$ $=630 \mathrm{~nm}$ dengan menggunakan metode fenat (APHA-AWWA-WEF, 1998).

\section{Analisis Data}

Efisiensi penjerapan amonia dihitung dengan membandingkan antara konsentrasi amonia sebelum dan sesudah proses adsorpsi dengan menggunakan persamaan (1) berikut (Lo et al., 2012).

$$
\text { Efisiensi }=\frac{\mathrm{C}_{\mathrm{o}}-\mathrm{C}_{\mathrm{eq}}}{\mathrm{C}_{\mathrm{o}}} \times 100 \%
$$

$\mathrm{C}_{\mathrm{o}}$ adalah konsentrasi awal amonia $(\mathrm{mg} / \mathrm{L})$ dan $\mathrm{C}_{\text {eq }}$ adalah konsentrasi amonia setelah adsorpsi (mg/L).

Adsorpsi secara batch dianalisis dengan pendekatan isotherm Langmuir dan Freundlich. Model Freundlich dituliskan dengan Persamaan (2) berikut (Wahab et al., 2010).

$$
\mathrm{q}_{\mathrm{eq}}=\mathrm{K}_{\mathrm{F}} \mathrm{C}_{\mathrm{eq}}{ }^{1 / \mathrm{n}}
$$

$\mathrm{q}_{\mathrm{eq}}$ adalah kandungan amonia dalam abu terbang bagas yang berada pada kesetimbangan ( $\mathrm{mg} / \mathrm{g})$, $\mathrm{K}_{\mathrm{F}}$ adalah konstanta persamaan Freundlich, $\left((\mathrm{mg} / \mathrm{g}) /(\mathrm{L} / \mathrm{mg})^{1 / \mathrm{n}}\right)$, dan $\mathrm{C}_{\text {eq }}$ adalah konsentasi amonia limbah yang berada pada kesetimbangan $(\mathrm{mg} / \mathrm{L})$. Model ini termasuk persamaan empiris yang paling awal digunakan untuk mendiskripsikan data kesetimbangan adsorpsi.

Model Langmuir dituliskan dengan Persamaan (3) berikut (Wahab et al., 2010).

$\mathrm{q}_{\mathrm{eq}}=\frac{\mathrm{Q}^{\circ} \mathrm{b} \mathrm{C}_{\mathrm{eq}}}{1+\mathrm{bC}_{\mathrm{eq}}}$

$\mathrm{Q}^{\circ}$ dan b adalah konstanta persamaan Langmuir. Model ini berasumsi permukaan adsorben seragam, semua molekul teradsorpsi tidak saling berinteraksi, semua molekul teradsorpsi melalui mekanisme yang sama, dan terbentuk monolayer.

Model terbaik dievaluasi dengan mencari koefisien korelasi $\left(\mathrm{R}^{2}\right)$ dan mean squared error (MSE) yang dinyatakan dengan persamaan berikut (Assefi et al., 2013):

$\mathrm{R}^{2}=1-\frac{\sum_{\mathrm{p}=1}^{\mathrm{p}}\left(\mathrm{d}_{\mathrm{p}}-\mathrm{o}_{\mathrm{p}}\right)^{2}}{\sum_{\mathrm{p}=1}^{\mathrm{p}} \mathrm{O}^{2}}$

$\operatorname{MSE}=\frac{1}{\mathrm{p}} \sum_{\mathrm{p}=1}^{\mathrm{p}}\left(\mathrm{d}_{\mathrm{p}}-\mathrm{op}_{\mathrm{p}}\right)^{2}$

$\mathrm{d}_{\mathrm{p}}$ adalah data yang diperoleh dari percobaan dan $o_{p}$ adalah hasil perhitungan menggunakan model.

\section{HASIL DAN PEMBAHASAN}

Air limbah yang digunakan dalam penelitian ini mempunyai kadar amonia sekitar $10 \mathrm{mg} / \mathrm{L}$ dan $\mathrm{pH}$ limbah 7,06. Nilai $\mathrm{pH}$ ini sesuai dengan baku mutu limbah cair, yaitu $\mathrm{pH}$ 6-9. $\mathrm{pH}$ limbah juga merupakan faktor yang penting dalam penjerapan amonia. Penelitian ini pernah dilakukan oleh Thornton et al. (2007) yaitu adsorpsi amonium menggunakan zeolit. Penelitian yang dilakukan oleh Thornton et al. (2007) juga menunjukkan hasil yang sama bahwa adsorpsi ion amonium $\left(\mathrm{NH}_{4}^{+}\right)$ menggunakan zeolit yang optimum tercapai saat $\mathrm{pH}<8$. Peningkatan adsorpsi secara cepat ini berhubungan dengan pembentukan hidrokso yang berbeda dengan saat terjadi kenaikan $\mathrm{pH}$ larutan.

Amonia berada di dalam air dalam dua bentuk yaitu berupa ion amonium $\left(\mathrm{NH}_{4}^{+}\right)$ atau non-ion amonium $\left(\mathrm{NH}_{3}\right)$, keseimbangan amonium dalam larutan sangat dipengaruhi oleh pH (Körner et al., 2001). Hal ini menunjukkan bahwa hanya dalam bentuk ionnya amonium dapat dihilangkan dari larutan dengan pertukaran ion. Pada $\mathrm{pH} 8$ dan dibawahnya, kebanyakan amonium berada dalam bentuk ionnya. Oleh karena itu sangat mungkin diasumsikan bahwa kondisi-kondisi ini sangat baik untuk proses penghilangan ion amonium (Thornton et al., 2007). Di atas pH 8, kesetimbangan bergeser dengan cepat ke arah amonium dalam bentuk bukan ionnya $\left(\mathrm{NH}_{3}\right)$ dan meningkatnya $\mathrm{pH}$ kurang baik untuk proses penghilangan amonium. Beberapa penelitian menunjukkan bahwa pada $\mathrm{pH}$ dibawah 8 terjadi peningkatan jumlah ion hidrogen dalam larutan, sehingga menyediakan cukup banyak rongga untuk 


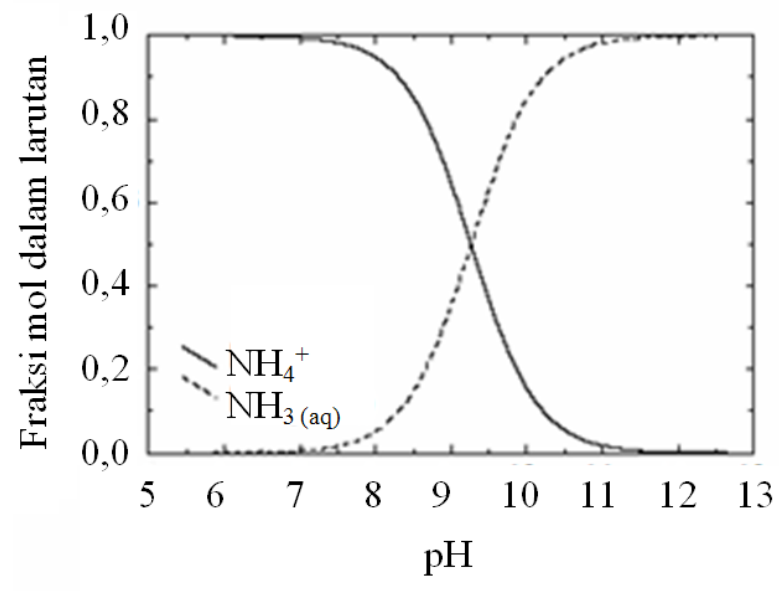

Gambar 1. Diagram perilaku ammonia dalam larutan (Handayani dan Widiastuti, 2009)

kompetisi terjadinya pertukaran (Hedstrom et al., 2001).

Menurut Handayani dan Widyasturi (2009), perilaku amonia dalam larutan yaitu bahwa amonia pada $\mathrm{pH} 5$ sampai 7 berbentuk ion amonium $\left(\mathrm{NH}_{4}^{+}\right)$, yang merupakan spesies utama yang dapat membuat terjadinya pertukaran ion dengan kation-kation yang berada dalam zeolit. Sehingga pada kondisi ini efisiensi penghilangan ammonium tinggi. Namun pada $\mathrm{pH}$ di atas 10 dimana $\mathrm{NH}_{3}$ merupakan spesies dominannya, efisiensi penghilangan ammonium rendah. Hal ini berhubungan dengan kemampuan pertukaran ion dalam bentuk utama $\mathrm{NH}_{3}$ sangat rendah. Perilaku amonia dalam larutan ditunjukkan pada Gambar 1.

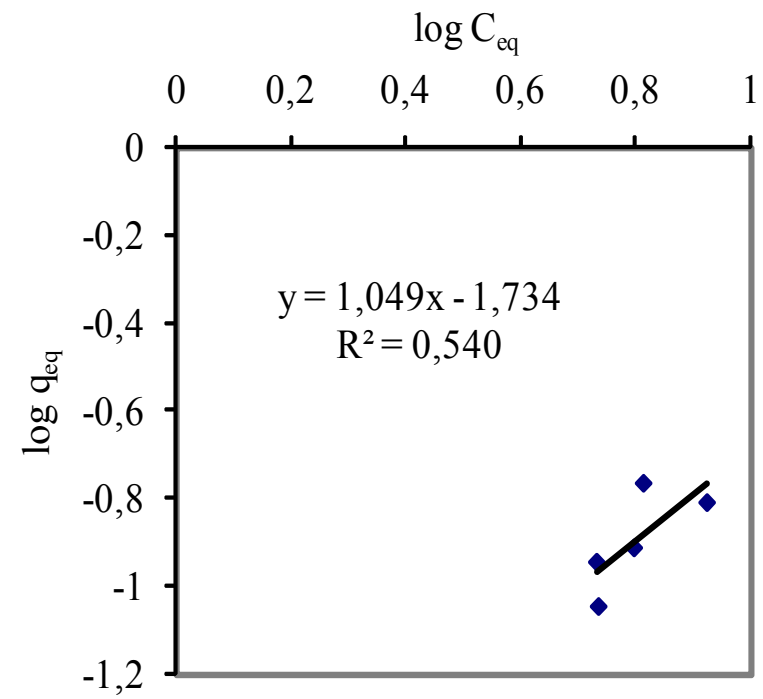

Gambar 3. Linearisasi persamaan Freundlich $(t=$ 1 jam, $\mathrm{V}=100 \mathrm{ml}$ )

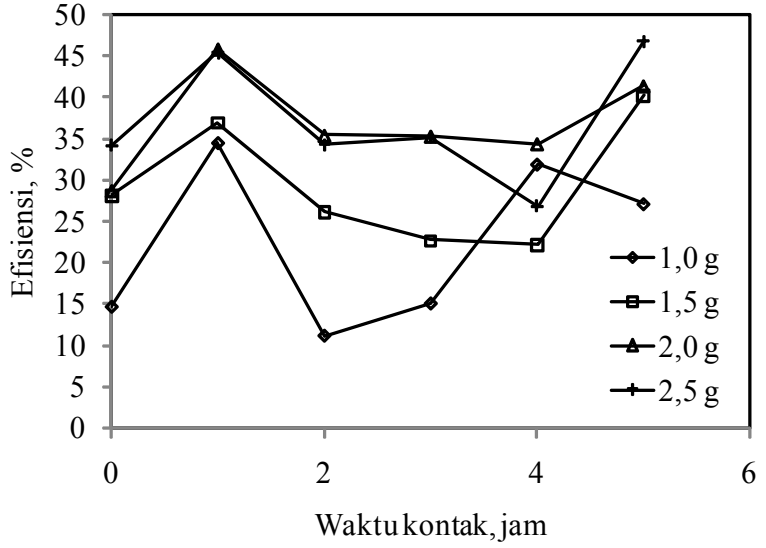

Gambar 2. Efisiensi Penurunan amoniak versus waktu kontak menggunakan variasi berat abu terbang bagas

\section{Penentuan Berat dan Waktu Kontak Optimum Menggunakan Abu Terbang Bagas}

Hasil dari penentuan berat dan waktu kontak optimum menggunakan abu terbang bagas disajikan pada Gambar 2. Dari Gambar 2 dapat diketahui bahwa adsorpsi secara batch menggunakan abu terbang bagas didapatkan kondisi optimum berat abu terbang bagas 2 gram dengan waktu kontak 1 jam yaitu dengan persentase removal amonia terbesar $45,72 \%$.

Data adsorpsi secara batch menggunakan abu terbang bagas kemudian dianalisis dengan melinearkan persamaan (2) dan (3). Hasil analisis menggunakan persamaan Freundlich dan Langmuir disajikan dalam Gambar 3 dan 4.

Dari Gambar 3 dan 4 dapat diketahui bahwa untuk persamaan Freundlich didapatkan

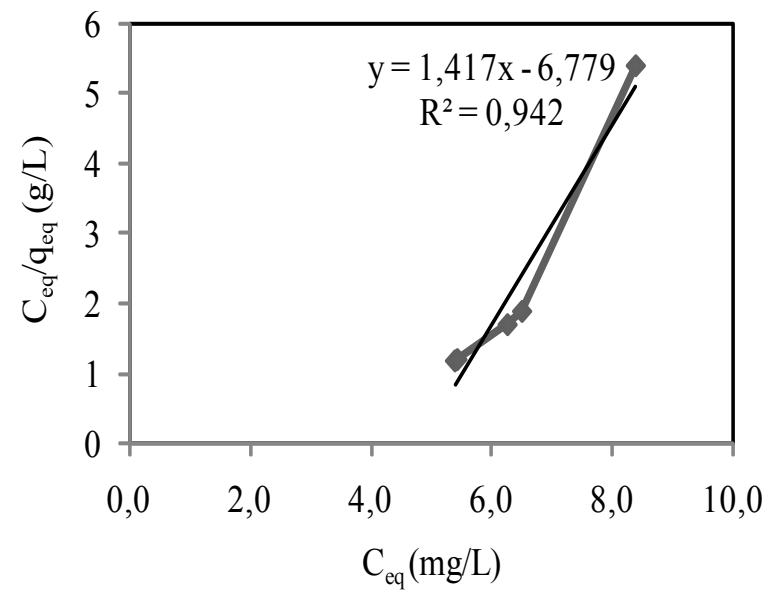

Gambar 4. Linearisasi persamaan Langmuir $(\mathrm{t}=1$ jam, $\mathrm{V}=100 \mathrm{ml})$ 
koefisien korelasi $\mathrm{R}^{2}=0,540$; nilai $\mathrm{K}_{\mathrm{F}}=2,45$; dan $1 / \mathrm{n}=1,049$ sedangkan untuk persamaan Langmuir didapatkan $\mathrm{R}^{2}=0,9424$; nilai $\mathrm{Q}^{\circ}=0,706$ $\mathrm{mg} / \mathrm{g}$; dan nilai $\mathrm{b}=0,209 \mathrm{~L} / \mathrm{mg}$. Dari persamaan (5) diperoleh $\mathrm{MSE}=0,45 \%$ untuk persaman Freundlich dan $\mathrm{MSE}=9,17 \%$ untuk persamaan Langmuir. Nilai koefisien korelasi $\left(\mathrm{R}^{2}\right)$ untuk persamaan Langmuir lebih besar daripada persamaan Freundlich. Dengan demikian, untuk penelitian adsorpsi secara batch menggunakan abu terbang bagas lebih cocok menggunakan model persamaan Langmuir. Nilai MSE persamaan Langmuir kurang dari 10\%, sehingga layak untuk digunakan. Adapun berat optimum abu terbang bagas 2 gram dengan waktu kontak 1 jam.

\section{KESIMPULAN DAN SARAN \\ Kesimpulan}

Adsorpsi amonia dalam limbah cair industri penyamakan kulit menggunakan abu terbang bagas secara batch yang optimum dilakukan dengan menggunakan berat abu terbang bagas 2 gram, waktu kontak 1 jam dengan efisiensi $45,72 \%$. Dari hasil data analisis, model yang paling baik adalah persamaan Langmuir dengan koefisien korelasi $\left(\mathrm{R}^{2}\right)$ 0,9424.

\section{Saran}

Penelitian ini belum mampu menurunkan kadar amonia sampai memenuhi baku mutu, sehingga perlu dilakukan penelitian lanjutan dengan menggunakan abu terbang bagas yang diseragamkan ukuran partikelnya dan dikombinasikan dengan adsorben yang lain.

\section{UCAPAN TERIMA KASIH}

Penulis mengucapkan terima kasih kepada Kepala Balai Besar Kulit, Karet dan Plastik atas pemberian izin penggunaan fasilitas peralatan laboratorium selama pelaksanaan penelitian. Kepada Bapak Sujarwoko, Bapak Fajar Majidi, Bapak Suharto, Ibu Ira Yuni Pantiwardani, dan Ibu Esti Purwanti kami ucapkan terima kasih atas kerjasamanya.

\section{DAFTAR PUSTAKA}

APHA-AWWA-WEF, 1998. Standard Method for the Examination of Water and Wastewater, 20th ed., American Public
Health Association, Washington.

Assefi, P., Ghaedi, M., Ansari, A., Habibi, M. H. and Momeni, M. S., 2013. Artificial neural network optimization for removal of hazardous dye Eosin $\mathrm{Y}$ from aqueous solution using $\mathrm{Co}_{2} \mathrm{O}_{3}$-NP-AC: Isotherm and kinetics study, Journal of Industrial and Engineering Chemistry, 2013: 1-9.

Gubernur Kepala Daerah Istimewa Yogyakarta, 2010. Keputusan Gubernur Kepala Daerah Istimewa Yogyakarta nomor 7/KPTS/2010 tentang Baku Mutu Limbah Cair Bagi Kegiatan Industri di Propinsi Daerah Istimewa Yogyakarta.

Handayani, N. dan Widyastuti, N., 2009. Adsorpsi ammonium $\left(\mathrm{NH}^{4+}\right)$ pada zeolit berkarbon dan zeolit A yang disintesis dari abu dasar batu bara PT. Ipmomi secara batch, Skripsi, Institut Teknologi Sepuluh Nopember.

Hedström, A., 2001. Ion exchange of ammonium in zeolites: A literature review, Journal of Environmental Engineering, 127(8): 673681.

Irmanto dan Suyata, 2009. Penurunan Kadar amonia,, nitrit, dan nitrat limbah cair industri tahu menggunakan arang aktif dari ampas kopi, Molekul, 4(2): 105-114.

Jafarpour, M., Foolad, A., Mansouri, M., Nikbakhsh, Z., and Saeedizade, H., 2010. Ammonia removal from nitrogenous industrial waste water using iranan natural zeolite of clinoptilolite type, World Academy of Science, Engineering and Technology, 70(2010): 939-945.

Körner, S., Das, S. K., Veenstra, S., and Vermaat, J. E., 2001. The effect of $\mathrm{pH}$ variation at the ammonium/ammonia equilibrium in wastewater and its toxicity to Lemna gibba, Aquatic Botany, 71(1): 71-78.

Kushwaha, J. P., Srivastava, V. C., and Mall, I. D., 2010. Treatment of dairy wastewater by commercial activated carbon and bagasse fly ash: Parametric, kinetic and equilibrium modelling, disposal studies, Bioresource Technology, 101(10): 3474-3483.

Lataye, D. H., Mishra, I. M., and Mall, I. D., 2008. Adsorption of 2-picoline onto bagasse fly ash from aqueous solution, Chemical Engineering Journal, 138(1): 35-46. 
Li, X., Lin, C., Wang, Y., Zhao, M., and Hou, Y., 2010. Clinoptilolite adsorption capability of ammonia in pig farm, Procedia Environmental Sciences, 2: 1598-1612.

Lo, S. F., Wang, S. Y., Tsai, M. J., and Lin, L. D., 2012. Adsorption capacity and removal efficiency of heavy metal ions by Moso and Ma bamboo activated carbons, Chemical Engineering Research and Design, 90(9): 1397-1406.

Luo, J., Shen, H., Markström, H., Wang, Z., and Niu, Q., 2011. Removal of $\mathrm{Cu}^{2+}$ from aqueous solution using fly ash, Journal of Minerals and Materials Characterization and Engineering, 10(6): 561-571.

Rezakazemi, M., Shirazian, S., and Ashrafizadeh, S. N., 2012. Simulation of ammonia removal from industrial wastewater streams by means of a hollow-fiber membrane contactor, Desalination, 285: 383-392.

Srivastava, V. C., Prasad, B., Mishra, I. M., Mall, I. D., and Swamy, M. M., 2008. Prediction of breakthrough curves for sorptive removal of phenol by bagasse fly ash packed bed, Industrial and Engineering Chemistry Research, 47(5): 1603-1613.

Subramanian, S., Pande, G., De Weireld, G., Giraudon, J. M., Lamonier, J. F., and Batra, V. S., 2013. Sugarcane bagasse fly ash as an attractive agro-industry source for VOC removal on porous carbon, Industrial Crops and Products, 49: 108-116.
Thornton, A., Pearce, P., and Parsons, S. A., 2007. Ammonium removal from solution using ion exchange on to MesoLite, an equilibrium study, Journal of Hazardous Materials, 147(3): 883-889.

Uğurlu, M. and Karaoğlu, M. H., 2011. Adsorption of ammonium from an aqueous solution by fly ash and sepiolite: Isotherm, kinetic and thermodynamic analysis, Microporous and Mesoporous Materials, 139(1): 173-178.

Wahab, M. A., Jellali, S., and Jedidi, N., 2010. Ammoniumbiosorption onto sawdust:FTIR analysis, kinetics and adsorption isotherms modeling, Bioresource Technology, 101(14): 5070-5075.

Wasewar, K. L., Prasad, B., and Gulipalli, S., 2009. Adsorption of selenium using bagasse fly ash. Clean-Soil, Air, Water, 37(7): 534543.

Zheng, H., Han, L., Ma, H., Zheng, Y., Zhang, H., Liu, D., and Liang, S., 2008. Adsorption characteristics of ammonium ion by zeolite 13X, Journal of Hazardous Materials, 158(2): 577-584. 